\title{
Microstructure Evolution During Transient Liquid Phase Bonding of Alloy 617
}

\author{
F. Jalilian • M. Jahazi $\cdot$ R. A. L. Drew
}

Received: 27 February 2013/Revised: 26 March 2013/Accepted: 17 April 2013/Published online: 10 May 2013

(C) Springer Science+Business Media New York and ASM International 2013

\begin{abstract}
Transient liquid phase bonding was used to join Alloy 617 alloy using nickel-based filler metal (Ni-P $11 \mathrm{wt} \%$ ) with $\mathrm{P}$ as the melting point depressant element. The influences of interlayer thickness, 25.4 and $38.1 \mu \mathrm{m}$, bonding temperature, 1,065 and $1,150{ }^{\circ} \mathrm{C}$, and hold time, $5 \mathrm{~min}$ to $24 \mathrm{~h}$, on microstructure evolution in the joint area, the diffusion zone and the base metal were investigated. Specifically, the composition, type, and crystallography of precipitates were determined and their evolution was related to process variables. Joints were characterized using optical and electron microscopy as well as microhardness testing. The results were analyzed in the framework of the diffusion, classical nucleation and growth theory, and the operating mechanisms identified. Based on the results of the investigation, uniform microhardness and microstructure across the joints was obtained with the $25.4-\mu \mathrm{m}$-thick interlayer bonded at $1,150{ }^{\circ} \mathrm{C}$ during $24 \mathrm{~h}$.
\end{abstract}

Keywords Superalloy TLP bonding process $\cdot$ Joint microstructure $\cdot$ Alloy $617 \cdot$ BNi-6 P Phosphides $\cdot$ Carbides

F. Jalilian · M. Jahazi ( $₫)$

Department of Mechanical Engineering, École de technologie supérieure, Montreal, QC, Canada

e-mail: mohammad.jahazi@etsmtl.ca

F. Jalilian

e-mail: farzad.jalilian@mail.mcgill.ca

R. A. L. Drew

Mechanical \& Industrial Engineering, Concordia University,

Montreal, QC, Canada

\section{Introduction}

Alloys for the hot sections of land-based gas turbines and aero-engines must have high temperature and cyclic oxidation resistance as well as an optimum combination of stress rupture and fatigue strength [1,2]. Superalloys, especially nickel base superalloys, are excellent candidates for such applications as they exhibit outstanding strength and surface stability at temperatures up to $85 \%$ of their absolute melting points [3]. Alloy 617 is a solid solution strengthened nickel base superalloy widely used in the aerospace and power generation industries because of its superior mechanical properties, corrosion, and oxidation resistance at elevated temperatures [1,2, 4-7]. The alloy is known for its good mechanical properties and a stable microstructure, especially after high temperature service when compared with Alloy 625 and HastelloyX [8].

Fusion welding is the most widely used technique for joining parts made of Alloy 617 and while the alloy is reputed for its good weldability, it commonly suffers from heat-affected zone (HAZ) cracking before and after post weld heat treatment. Transient liquid phase (TLP) bonding, also known as diffusion brazing, has become an interesting alternative to fusion welding or classical brazing techniques for joining highly sensitive and high reliability components made of $\mathrm{Ni}$ base superalloys $[9,10]$. Indeed, the technique does not have the commonly observed shortcomings of fusion welding and presents clear advantages over classical diffusion bonding as it does not require high pressures and clamping forces. Moreover, TLP joints are characterized by uniform composition profiles and less sensitivity to surface defects and variations in gap sizes [11-13].

In the TLP bonding process, a thin interlayer alloy containing the melting point depressant (MPD) element, 
acting as the bonding agent, is placed between the two base metal surfaces. The joining operation is carried out at a temperature between the liquidus of the interlayer and the solidus of the base metal [14-16]. The thickness and composition of the interlayer, hold time, and bonding temperature are among the most important process parameters. The initial conditions of the material such as its grain size, surface preparation, and heat treatment are also important considerations in the TLP bonding process [17]. The optimization of the parameters is of great importance as the life cycle of the component is significantly dependent on the quality of the joints.

The TLP process can be classified into three main stages: liquation of the interlayer, isothermal solidification, and homogenization. Isothermal solidification is the most important stage in TLP bonding and it requires long hold times. If isothermal solidification is not fully achieved, part of the liquid phase remains in the bonding area and forms brittle phases upon cooling. These brittle phases are detrimental to the mechanical properties of the joint and reduce the component life. An optimum process would be the one allowing for complete isothermal solidification in a minimum of time and avoid the formation of brittle phases [16, 18].

To date, the majority of published research on Alloy 617 has been focused on improving mechanical properties and the evolution of the alloy microstructure under high temperature service conditions. Very few reports have been reported on TLP bonding of Alloy 617. It is important to note that achieving optimized process conditions and largescale application of the TLP process requires technical data related to the identification of phases and precipitates, the diffusion mechanism of the MPD element and the effect of bonding temperature, hold time and thickness of the interlayer on joint microstructure. Such data are scarce in the literature and this study intends to provide some insight in this regard.

In this study, TLP bonding of Alloy 617 using Ni-11\% P (American Welding Society designation BNi-6) filler metal is investigated. The influences of the interlayer thickness, bonding temperature and hold times on the characteristics of eutectic phases, morphology, distribution, and composition of second phase particles are studied and the governing mechanisms are discussed. The relationships between joint microstructure and mechanical properties of TLP-bonded specimens are also studied.

\section{Experimental Procedure}

\section{Materials}

Test specimens, $25 \times 5 \mathrm{~mm}^{2}$ were machined out from the $1-\mathrm{mm}$-thick sheet Alloy 617 as received material. They were then annealed at $1,177^{\circ} \mathrm{C}$ for $1 \mathrm{~h}$ and air cooled before the experiments. The filler metal, $\mathrm{Ni}-11 \mathrm{wt} \% \mathrm{P}$ alloy with thicknesses of 25.4 and $38.1 \mu \mathrm{m}$, was cut to dimensions equal to that of the base metal specimens. The chemical composition of the filler metal and the base metal are given in Table 1. Figure 1 shows the microstructure of the as-received material obtained by optical microscopy. The average grain size of the matrix was $40 \mu \mathrm{m}$ and some fine disconnected carbides were visible within the $\gamma$ matrix.

\section{Experimental Techniques}

Before the TLP operation, the two bonding surfaces were ground and polished with the final polishing step using $0.05 \mu \mathrm{m} \mathrm{Al}_{2} \mathrm{O}_{3}$. The interlayer was then inserted between the two base metal coupons and the sandwich was placed in a stainless steel fixture to hold the parts and to reduce metal flow during the joining process. Finally, each assembly was placed on a boron nitride tray inside the tube furnace. All samples were joined in the tube furnace for periods of time ranging from $5 \mathrm{~min}$ to $24 \mathrm{~h}$ at 1,065 and $1,150{ }^{\circ} \mathrm{C}$ under a vacuum of $1 \times 10^{-3} \mathrm{~Pa}$. After bonding, the specimens were sectioned through the middle in a plane perpendicular to the length of the sample. They were then polished and etched using Kalling's reagent $\left(5 \mathrm{~g} \mathrm{CuCl}_{2}+100 \mathrm{~cm}^{3}\right.$ $\mathrm{HCl}+100 \mathrm{~cm}^{3} \mathrm{C}_{2} \mathrm{H}_{5} \mathrm{OH}$ ).

The microstructure, chemical composition, and size distribution of the precipitates were examined using light and field emission gun scanning electron microscopy (FEG-SEM). The latter was equipped with electron backscattered diffraction (EBSD) and energy dispersive spectroscopy (EDS) systems. The depth of the diffusion layer was measured using the SEM at 1,000× magnification with each value reported representing an average of ten measurements. The values for precipitates sizes represent an average of 40-50 measurements on five different micrographs. The average width of the remaining "liquid" phase

Table 1 Chemical composition (wt\%) of the base metal and the filler material

\begin{tabular}{lllllllllll}
\hline Materials (wt\%) & $\mathrm{Cr}$ & $\mathrm{Co}$ & $\mathrm{Mo}$ & $\mathrm{Al}$ & $\mathrm{C}$ & $\mathrm{Ti}$ & $\mathrm{B}$ & $\mathrm{Zr}$ & $\mathrm{P}$ & $\mathrm{Ni}$ \\
\hline Inconel 617 & 22 & 12 & 9 & 1.2 & 0.07 & 0.3 & 0.0006 & $\ldots$ & $\ldots$ \\
Filler metal (BNi-6) & $\ldots$ & $\ldots$ & $\ldots$ & 0.01 & 0.02 & 0.01 & $\ldots$ & 0.01 & 10.8 & 90.64 \\
\hline
\end{tabular}


(non isothermally solidified phase) at the end of the TLP process (solidified phase) was measured on micrographs taken at $100 \times$ magnification with each point being an average of 50 measurements. X-ray diffraction (XRD) was performed with a $0.02^{\circ}$ step size with continuous time of 1 s/step through $2 \theta$ angles from $10^{\circ}$ to $130^{\circ}$. Vickers microhardness tests were carried out using a $10 \mathrm{~g}$ load and a $15 \mu \mathrm{m}$ spacing between indentations. Each data point in the microhardness profile is an average of three measurements (with an error range of $\pm 3 \mathrm{HV}$ ).

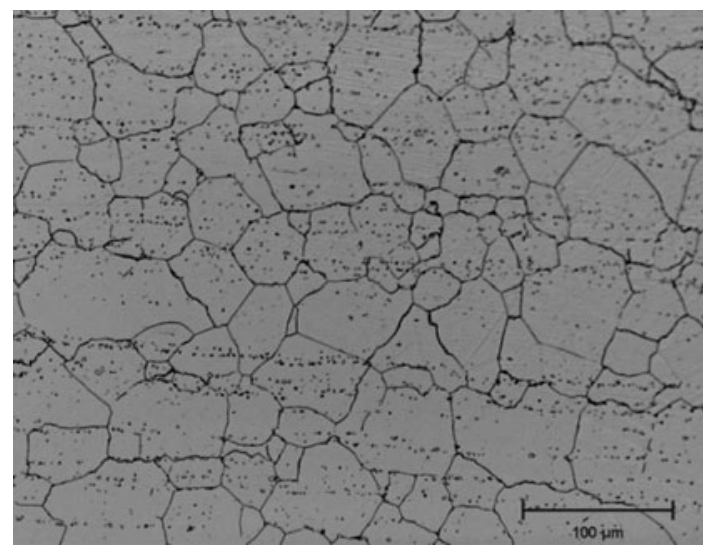

Fig. 1 Microstructures of Alloy 617 (base metal)

\section{Results and Discussion}

\section{Microstructures}

The TLP bonding process begins with the melting of the interlayer and the diffusion of phosphorous into the base metal. This diffusion results in the formation of a diffusion layer where a gradual change in phosphorus concentration is observed. Microstructural examination by optical microscopy revealed that hold at $1,065^{\circ} \mathrm{C}$ for $18 \mathrm{~h}$ using the 25.4- $\mu \mathrm{m}$-thick interlayer resulted in the complete elimination of the liquid phase. The $38.1 \mu \mathrm{m}$ interlayer had a solidification microstructure remaining after heating to $1,065{ }^{\circ} \mathrm{C}$ indicating that the liquid phase was still present even after 24-h hold (Fig. 2a-d). Increasing the bonding temperature to $1,150{ }^{\circ} \mathrm{C}$, reduced the complete isothermal solidification time from 18 to $14 \mathrm{~h}$ for the $25.4 \mu \mathrm{m}$ interlayer; however, for the thick interlayer, even after $24 \mathrm{~h}$ at $1,150{ }^{\circ} \mathrm{C}$, the liquid phase was not completely eliminated, as evidenced by the presence of solidified phase shown in Fig. 3(a-d).

The minimum and maximum thicknesses of the diffusion layer for all experimental conditions were measured. The evolution of the diffusion depth of phosphorous into the base metal is indicated in Table 2. The results indicate that increasing the interlayer thickness, bonding time and temperature increase the diffusion depth.
Fig. 2 Microstructures of joints at $1,065{ }^{\circ} \mathrm{C}$ (a) $5 \mathrm{~min}$ and (b) $18 \mathrm{~h}$ with $25.4 \mu \mathrm{m}$ interlayer, and (c) 5 min and (d) $24 \mathrm{~h}$ with $38.1 \mu \mathrm{m}$ interlayer
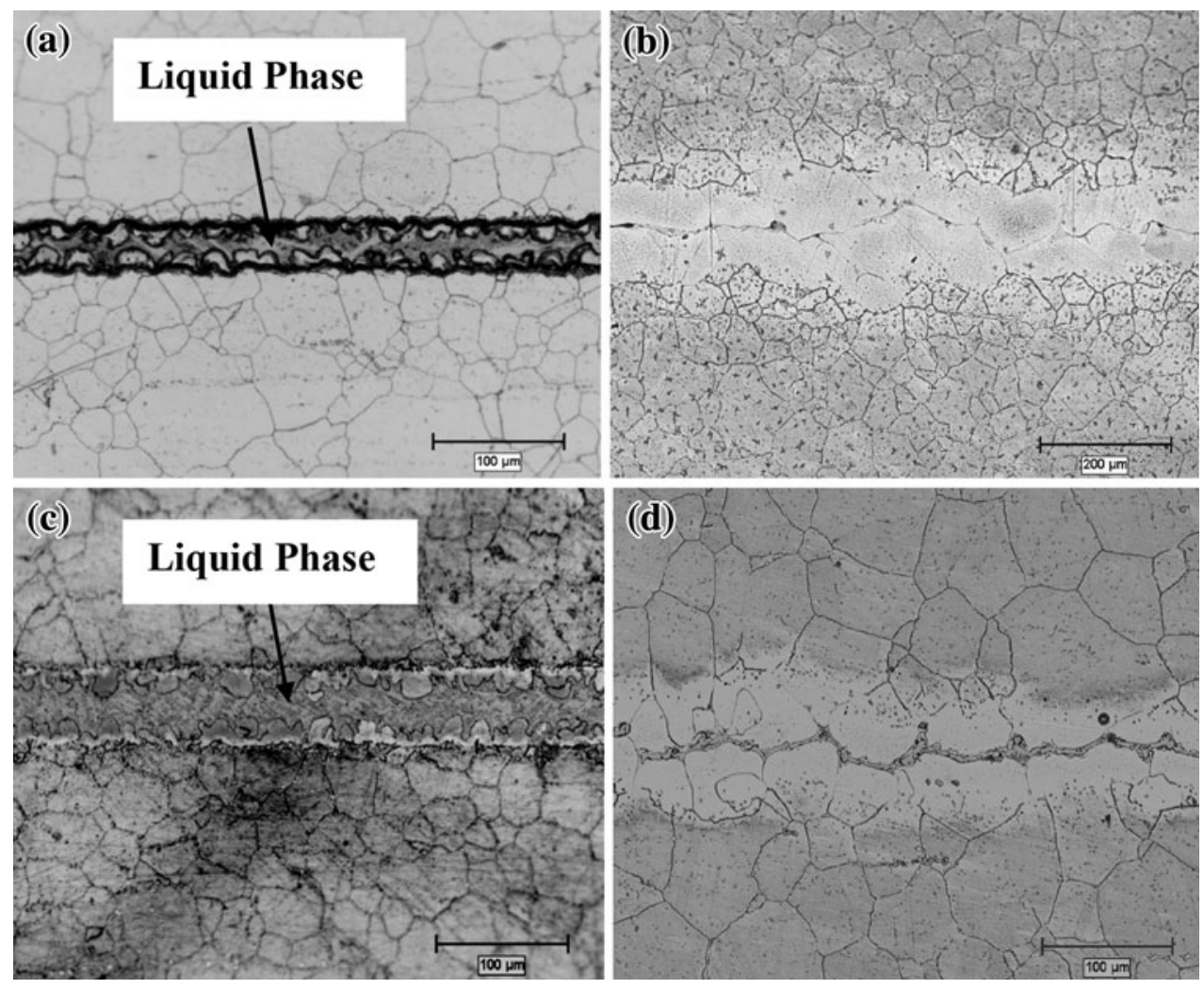
Fig. 3 Effect of the hold time on microstructure at $1,150{ }^{\circ} \mathrm{C}$ (a) 5-min and (b) 14-h hold time for $25.4 \mu \mathrm{m}$ interlayer (c) 5-min and (d) 24-h hold time for $38.1 \mu \mathrm{m}$ interlayer
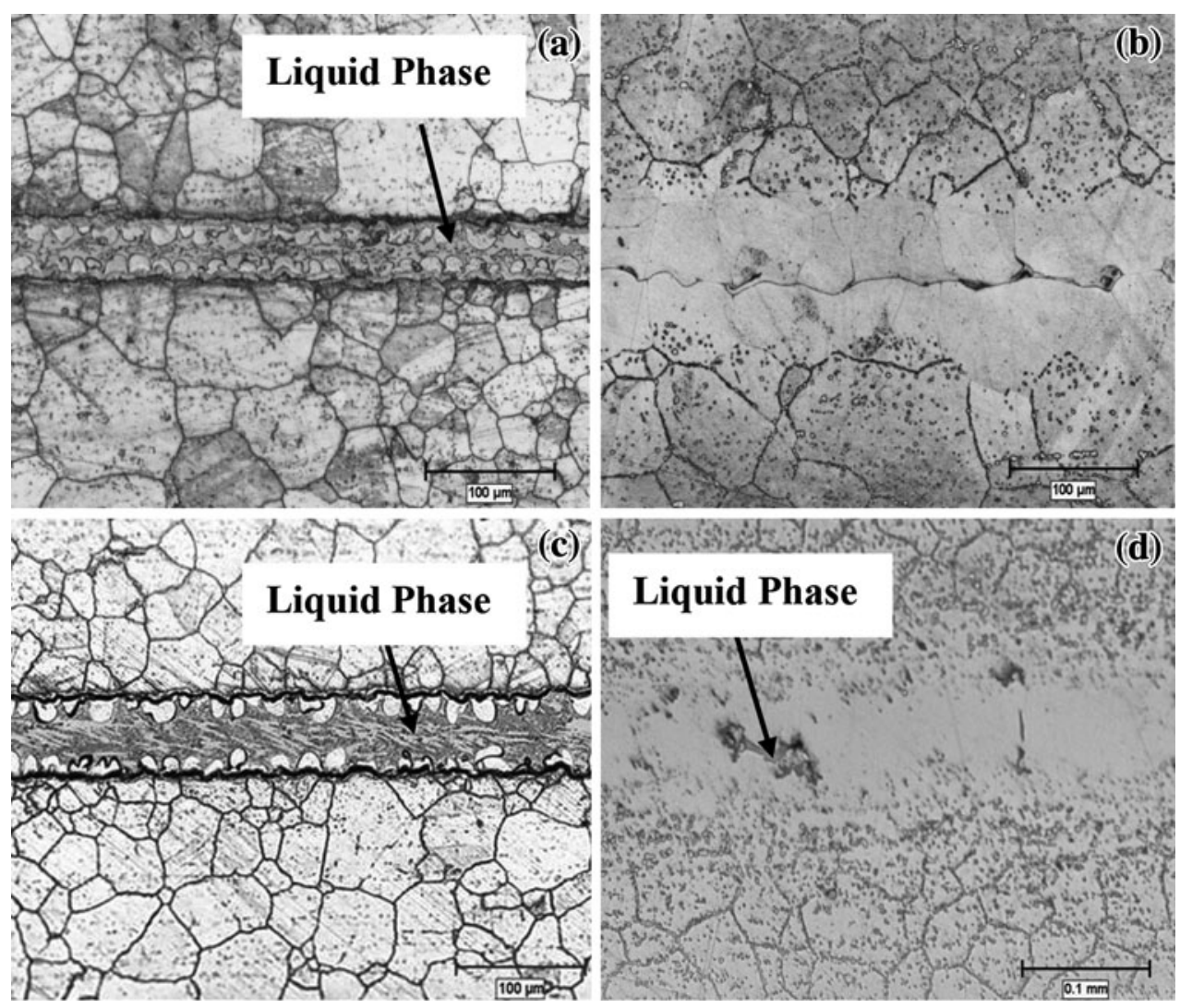

Table 2 The depth of the phosphorous diffusion based on bonding temperature, thickness of interlayer, and hold time

\begin{tabular}{|c|c|c|c|c|}
\hline \multirow[b]{2}{*}{ Diffusion depth: } & \multicolumn{2}{|c|}{ Low temperature $\left(1,065^{\circ} \mathrm{C}\right)$} & \multicolumn{2}{|c|}{ High temperature $\left(1,150{ }^{\circ} \mathrm{C}\right)$} \\
\hline & $25.4 \mu \mathrm{m}$ interlayer & $38.1 \mu \mathrm{m}$ interlayer & $25.4 \mu \mathrm{m}$ interlayer & $38.1 \mu \mathrm{m}$ interlayer \\
\hline $5 \mathrm{~min}$ & $2.5 \mu \mathrm{m}$ & $5 \mu \mathrm{m}$ & $6 \mu \mathrm{m}$ & $9 \mu \mathrm{m}$ \\
\hline $24 \mathrm{~h}$ & $65 \mu \mathrm{m}$ & $91 \mu \mathrm{m}$ & $105 \mu \mathrm{m}$ & $135 \mu \mathrm{m}$ \\
\hline
\end{tabular}

Fig. 4 Effect of hold time on the average width of the eutectic phase

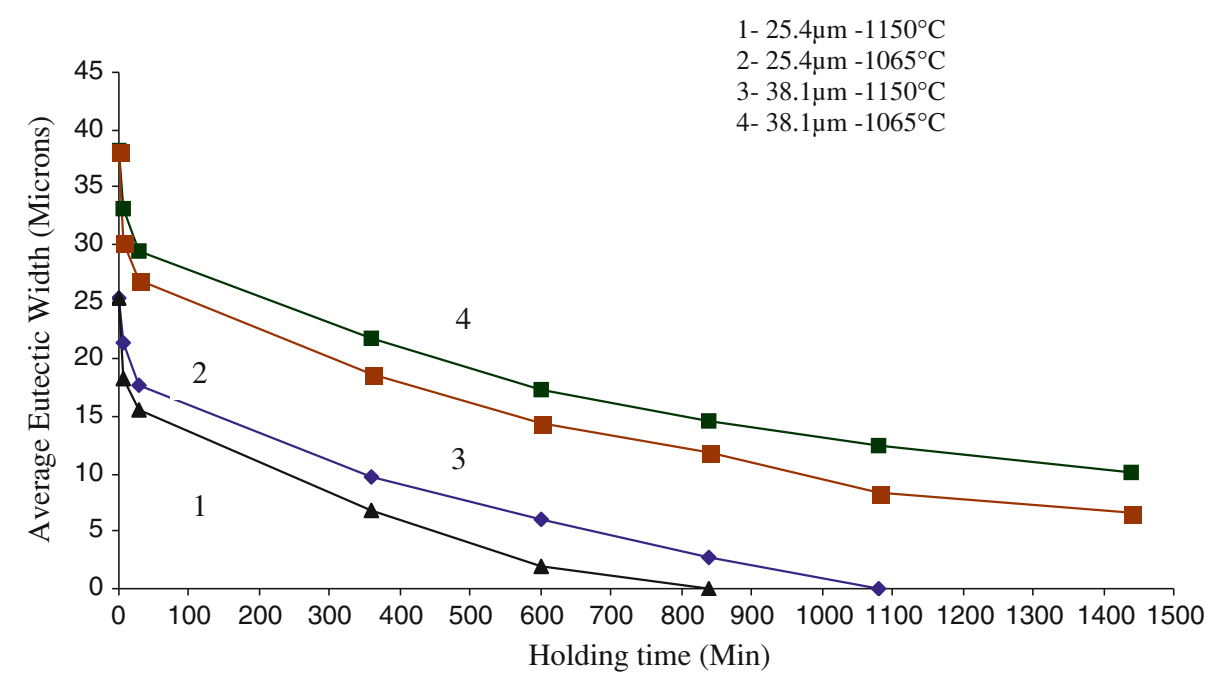




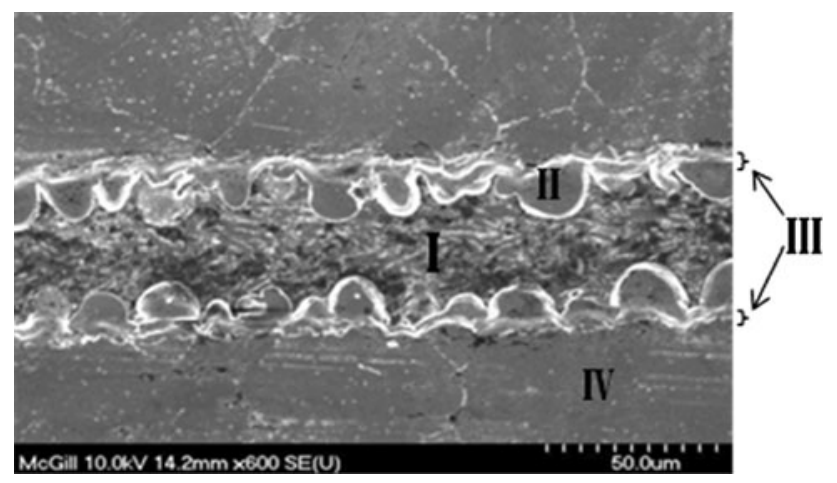

Fig. 5 The microstructure of joint area

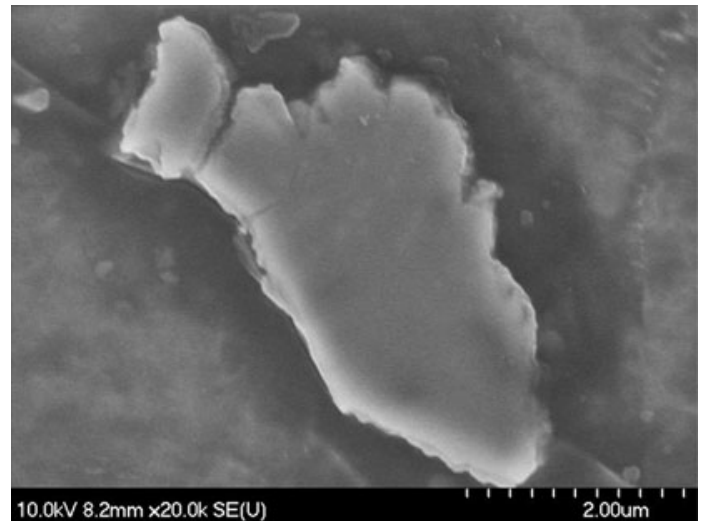

Fig. 6 Morphology of precipitates in the diffusion layer, $1065^{\circ} \mathrm{C}$, 10-h hold time with $25.4 \mu \mathrm{m}$ interlayer
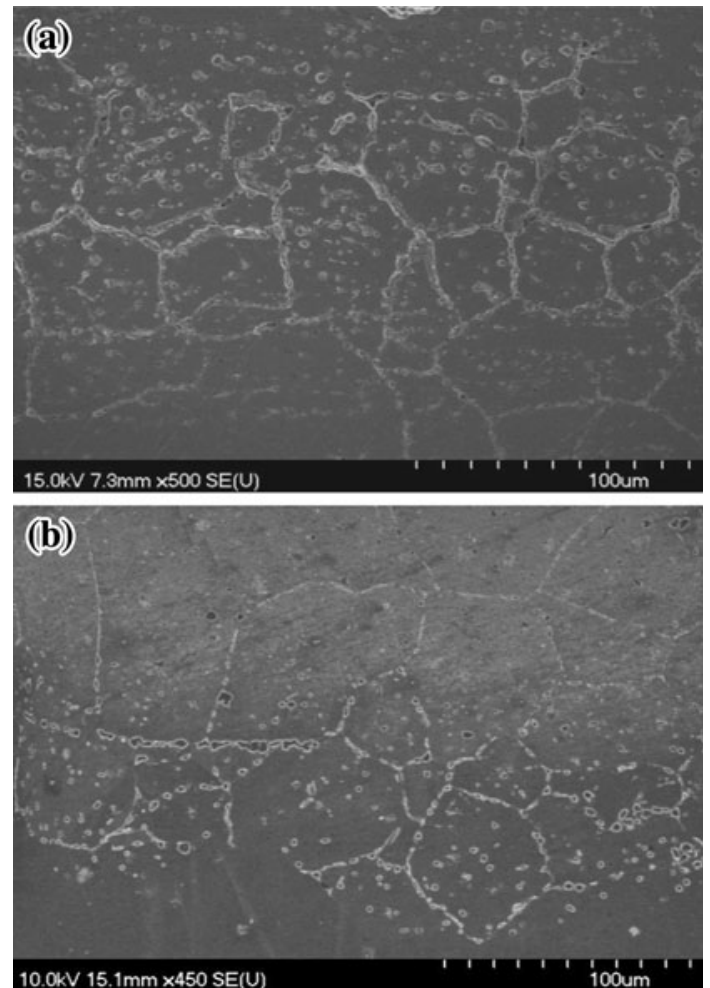

Fig. 7 Effect of hold time on the microstructure of diffusion layer with $25.4 \mu \mathrm{m}$ interlayer, (a) $10 \mathrm{~h}$ at $1,065^{\circ} \mathrm{C}$, (b) $14 \mathrm{~h}$ at $1,150{ }^{\circ} \mathrm{C}$
It was also found that, as the hold time was increased, so did the average size of the grains from the interlayer-base metal interface to the joint center. The effect of hold time on the average width of the liquid phase for the two testing temperatures is illustrated in Fig. 4. It can be seen that, by increasing the bonding temperature and the hold time, the elimination rate of the liquid phase was increased, thereby increasing the thickness of the diffusion layer. The behavior was independent of the thickness of the interlayer and was observed for both investigated thicknesses.

The microstructure in the joint area was characterized in four distinct regions as illustrated in Fig. 5: (I) the liquid (eutectic) phase formed when insufficient hold time for completing isothermal solidification was used, (II) the solidified grains at the interface of the base metal and interlayer, (III) the diffusion layer containing the precipitates, and (IV) the base metal microstructure containing some precipitates at the grain boundaries and inside the $\gamma$ grains.

Microstructural examination of the diffusion layer revealed irregularly shaped precipitates including some with blocky morphologies (Fig. 6). The influence of hold time on precipitates distribution is shown in Fig. 7.
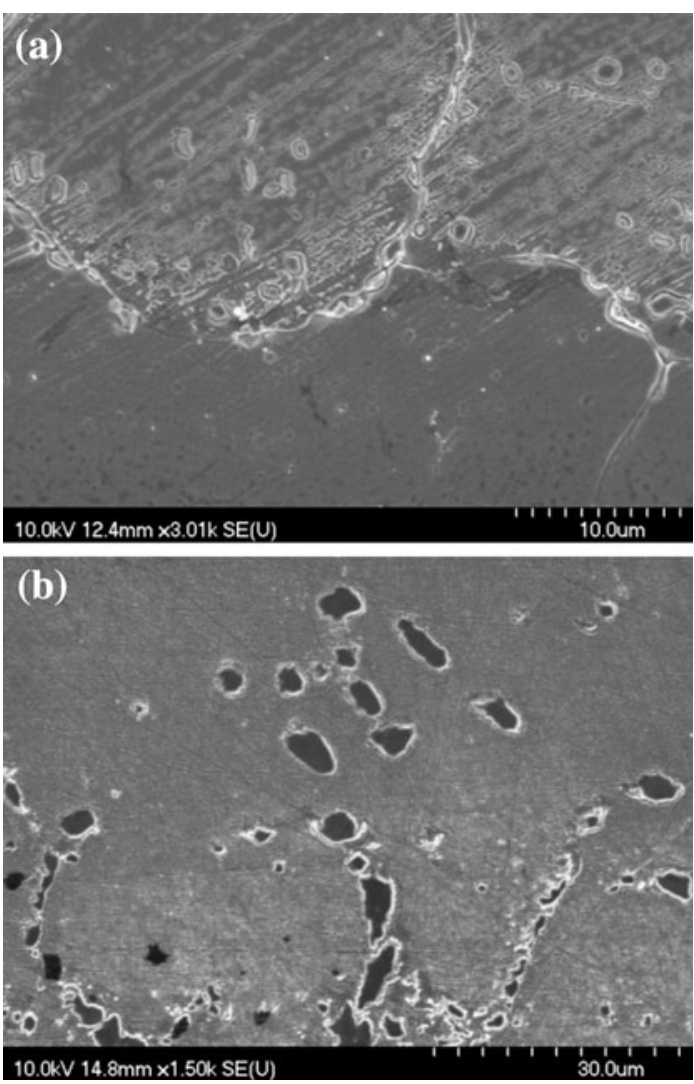

Fig. 8 The effect of hold time on precipitate sizes in the diffusion layer with $25.4 \mu \mathrm{m}$ interlayer and $1,065^{\circ} \mathrm{C}$ (a) 30-min and (b) 24-h hold time 
Microstructural examination indicated that for both testing temperatures with hold times above $10 \mathrm{~h}$ a large number of precipitates were present at the grain boundaries. The density of the precipitates gradually decreased from the boundary toward the center of the grains indicating that precipitation started initially at the grain boundaries and continued within the grains. Comparison between the results obtained in the present investigation and a previously published work using a boron-containing interlayer [19] indicated that the extent of precipitation with the phosphorus-containing interlayer is much smaller than with the boron containing one.

The evolution of precipitate size as a function of the hold time for the $1,065{ }^{\circ} \mathrm{C}$ temperature is illustrated in Fig. 8. As the hold time increases, so does the average size of the precipitates in the diffusion layer passing from about 0.65 to $3.45 \mu \mathrm{m}$ for the thin interlayer (Fig. 8a) and from 0.3 to $2.9 \mu \mathrm{m}$ for the thick interlayer (Fig. 8b). A similar trend was observed for the $1,150{ }^{\circ} \mathrm{C}$ bonding temperature where the average grain size increased from 0.91 to
Fig. 9 X-ray map analysis of irregular precipitates, within the $38.1 \mu \mathrm{m}$ interlayer at $1,065{ }^{\circ} \mathrm{C}$, and 10 -h hold time showing molybdenum phosphide precipitates

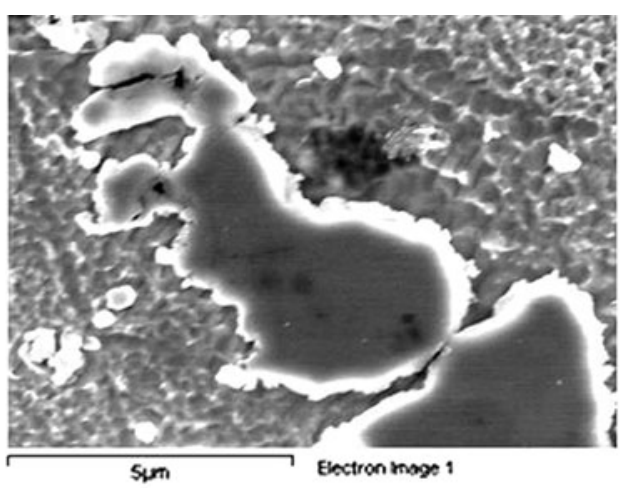

(a) SE

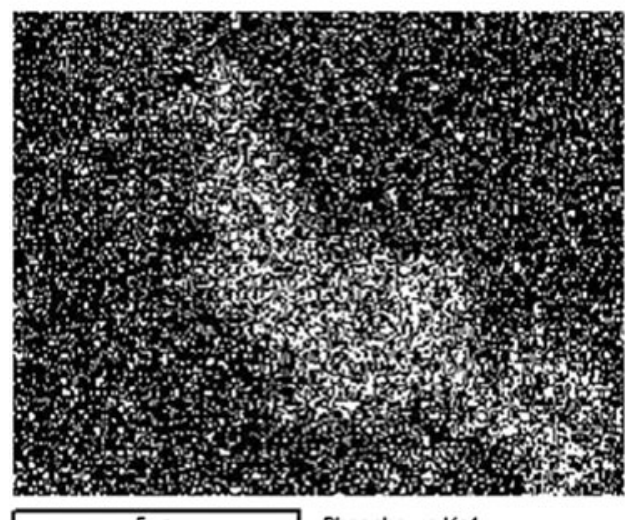

(c) $\mathrm{P}$

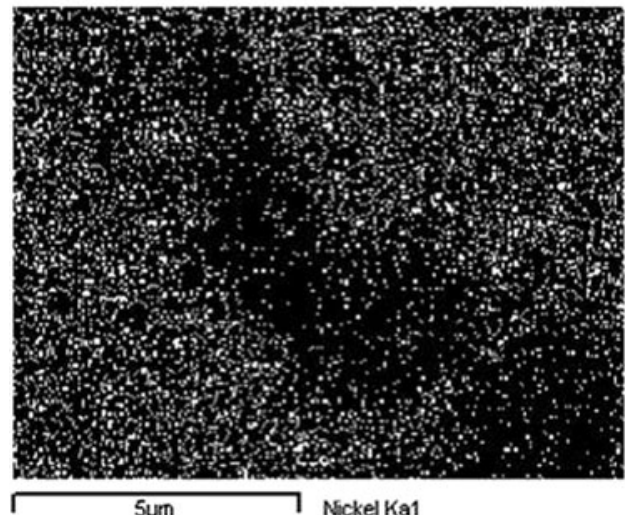

(e) $\mathrm{Ni}$

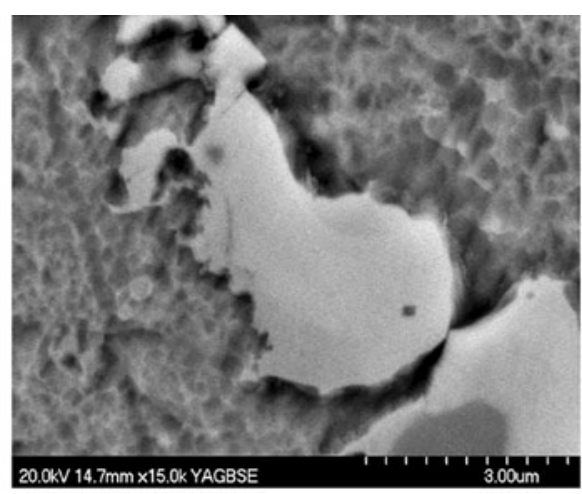

(b)

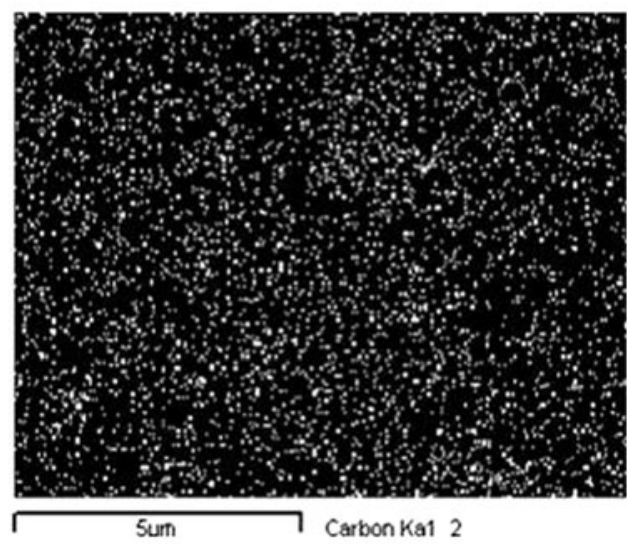

(d) $\mathrm{C}$

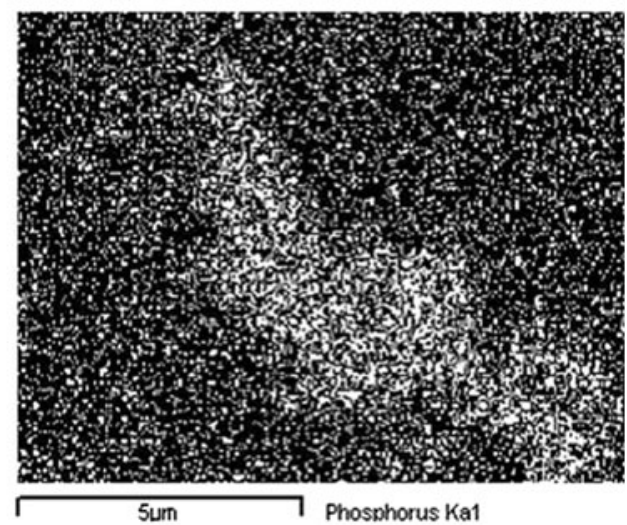

(f) $\mathrm{Mo}$ 
$3.81 \mu \mathrm{m}$ for the thin and from 0.59 to $3.42 \mu \mathrm{m}$ for the thick interlayer. The above results are interpreted in terms of the differences in diffusivities of the elements present in the microstructure. A comparison between the diffusivities of phosphorus $\left(D_{\mathrm{P}}=1.8 \times 10^{-11} \mathrm{~m}^{2} \mathrm{~s}^{-1}, D_{0}=0.49 \mathrm{~m}^{2} \mathrm{~s}^{-1}\right.$, and $\left.Q=284 \mathrm{~kJ} \mathrm{~mol}^{-1}[20-23]\right)$ and boron $\left(D_{\mathrm{B}}=6.22 \times\right.$ $10^{-11} \mathrm{~m}^{2} \mathrm{~s}^{-1}, D_{0}=0.14 \mathrm{~m}^{2} \mathrm{~s}^{-1}$, and $Q=226 \mathrm{~kJ} \mathrm{~mol}^{-1}$ $[22,24])$ in solid nickel indicates that phosphorus diffusion rate is significantly lower than that of boron. Thus, the time to complete isothermal solidification with the phosphorus-containing interlayer will be longer. Moreover, it is known that, under similar working conditions, the segregation of interstitial elements to interfaces is higher than the substitutional ones. Several reports in the literature confirm that boron occupies mostly interstitial positions in the Ni structure, while phosphorus occupies substitutional sites [25-27].

Low diffusivity of phosphorous, its substitutional position in the $\mathrm{Ni}$ lattice, and the increased thickness of the
Fig. 10 X-ray map analysis of the second group of precipitates, joint with $38.1 \mu \mathrm{m}$ interlayer at $1,065^{\circ} \mathrm{C}$ and 10 -h hold time showing carbides precipitates

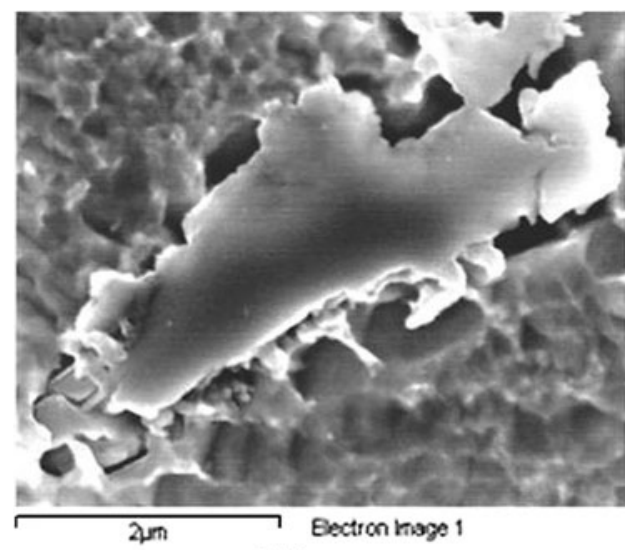

(a) SE

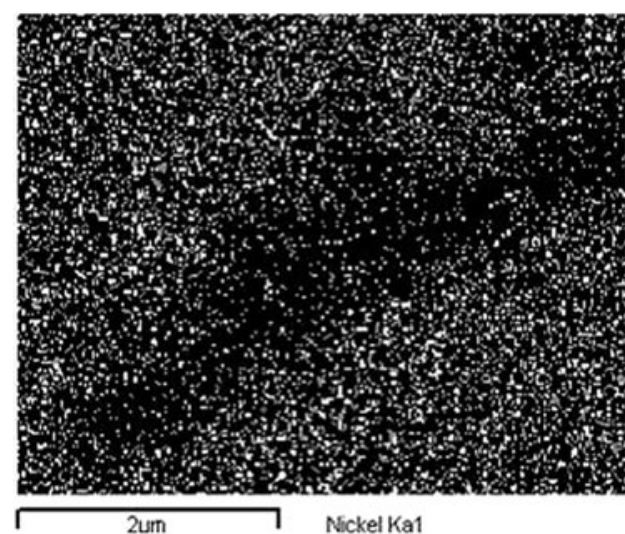

(c) $\mathrm{Ni}$

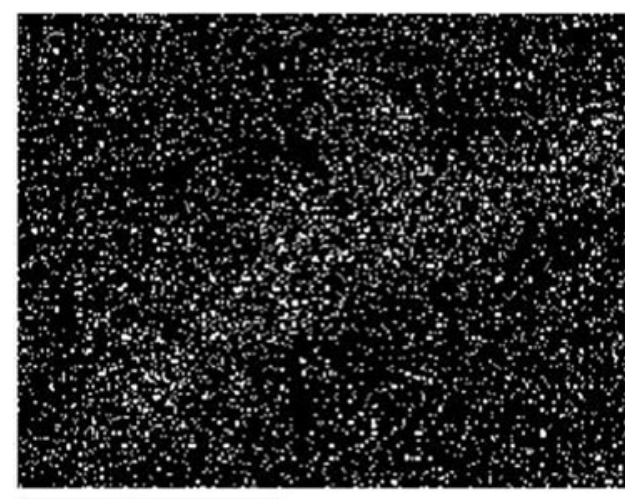

Carbon Ka1 2

(e) $\mathrm{C}$

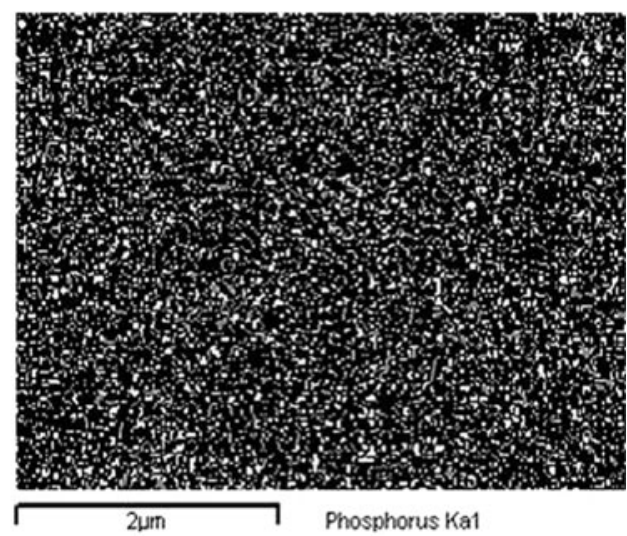

(b) $\mathrm{P}$

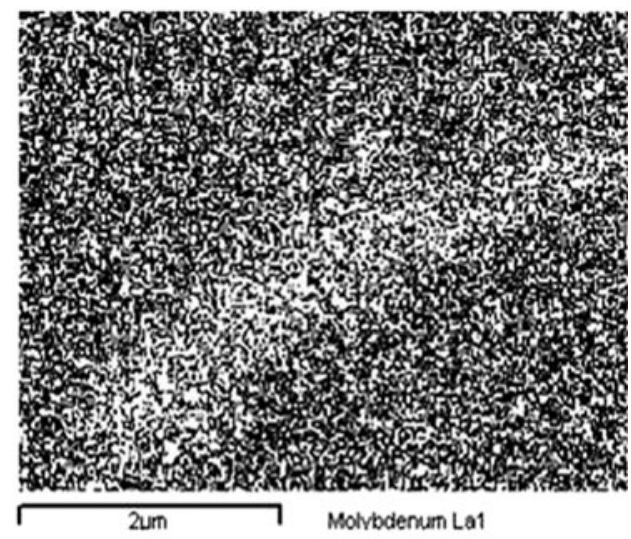

(d) Mo

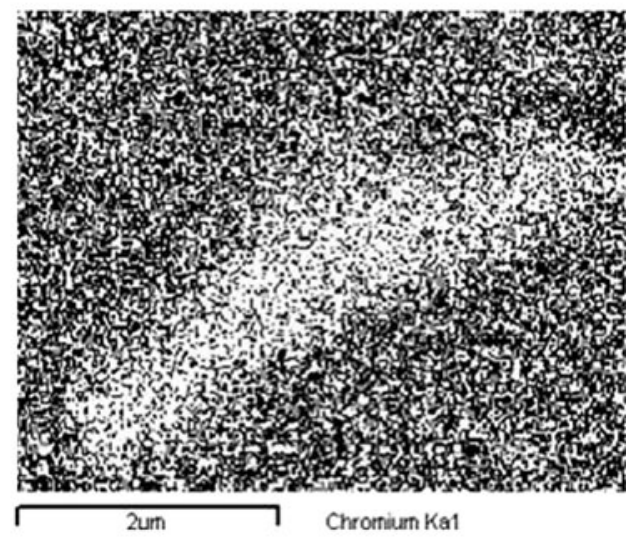

(f) $\mathrm{Cr}$ 
interlayer can be considered as the determining factors for the lower presence of precipitates when phosphorus is used. Finally, it is also important to note that a large fraction of precipitates and carbides, initially present in the microstructure of the interlayer and the base metal, did not dissolve during the TLP process and were still observable, in the base metal and the diffusion zone, at the end of the joining process.

Identification of the Precipitates

$\mathrm{M}(\mathrm{C}, \mathrm{N}), \mathrm{M}_{6} \mathrm{C}$, and $\mathrm{M}_{23} \mathrm{C}_{6}$ are the major carbides generally present in the microstructure of Alloy 617 [4, 28]. Among these, $\mathrm{M}_{23} \mathrm{C}_{6}$ has been observed in the temperature range 649-1,093 ${ }^{\circ} \mathrm{C}$ with a composition considered to be $\mathrm{Cr}_{21} \mathrm{Mo}_{2} \mathrm{C}_{6}$ [29]. $\mathrm{Ni}_{3} \mathrm{Al}\left(\gamma^{\prime}\right)$ and boride precipitates have also been reported for this alloy [29].

In this study, different types of precipitates in terms of morphology and composition were identified in the central region of the interlayer and in the diffusion layer. Specifically, two groups of precipitates with different chemical compositions were observed and identified in the diffusion layer. The first group was formed of irregular shape molybdenum phosphide precipitates, $\operatorname{Mo}_{x} \mathrm{P}_{y}$ (Fig. 9). The second group of precipitates had blocky and/or irregular morphologies and contained high concentrations of chromium, molybdenum, and carbon, indicating that they were carbides of the type $\mathrm{Mo}_{x} \mathrm{Cr}_{y} \mathrm{C}_{z}$ (Fig. 10).

EDS map analysis of the central region (region I) of the interlayer revealed the presence of phosphorous and nickel with significantly higher concentrations for phosphorous (Fig. 11). EBSD analysis revealed the presence of $\mathrm{Ni}_{3} \mathrm{P}$ precipitates in the non isothermally solidified phase as well as in the isothermally solidified grains (Fig. 12). The formation of the $\mathrm{Ni}_{3} \mathrm{P}$ phase can be justified when the amount of phosphorous present in the interlayer and the Ni-P binary phase diagram are considered [30].

EBSD and XRD analyses revealed that the precipitates formed as a result of phosphorous diffusion into the base metal were MoP, MoNiP, $\mathrm{Mo}_{3} \mathrm{P}$, or $\mathrm{Ni}_{3} \mathrm{P}$, while carbides were of the type $\mathrm{M}_{23} \mathrm{C}_{6}$ and MC. The EBSD patterns of phosphorus-containing phases, presented in Figs. 13 and 14 , indicate the presence of $\mathrm{MoP}(24.40 \mathrm{wt} \% \mathrm{P})$ and MoNiP with hexagonal crystal structure, and $\mathrm{Mo}_{3} \mathrm{P}$ (9.72 wt \%) and $\mathrm{Ni}_{3} \mathrm{P}(14.96 \mathrm{wt} \% \mathrm{P})$ with tetragonal crystal structures.
Fig. 11 The X-ray map analysis of the central region of the TLP joint or region I, $38.1 \mu \mathrm{m}$ interlayer at $1,150{ }^{\circ} \mathrm{C}$ bonding temperature and $10-\mathrm{h}$ hold time

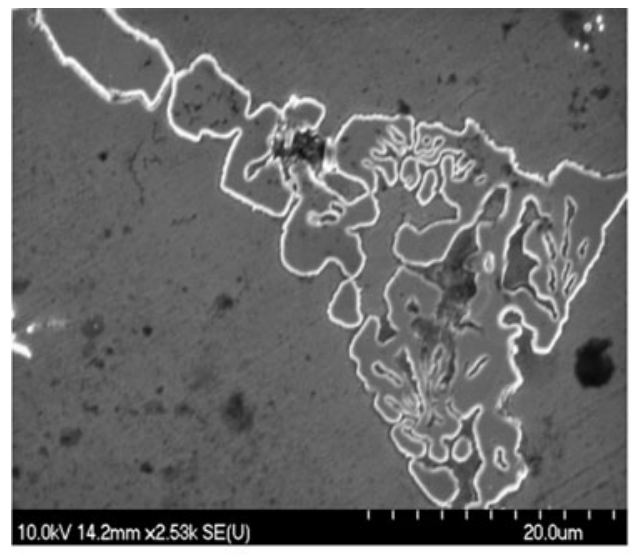

(a) SE

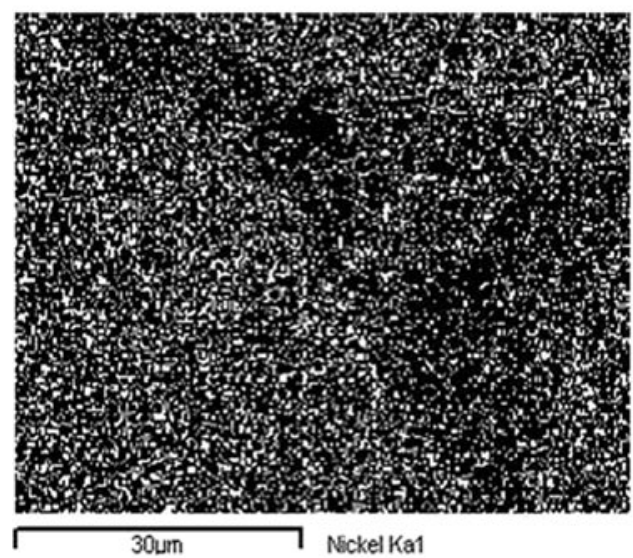

(c) $\mathrm{Ni}$

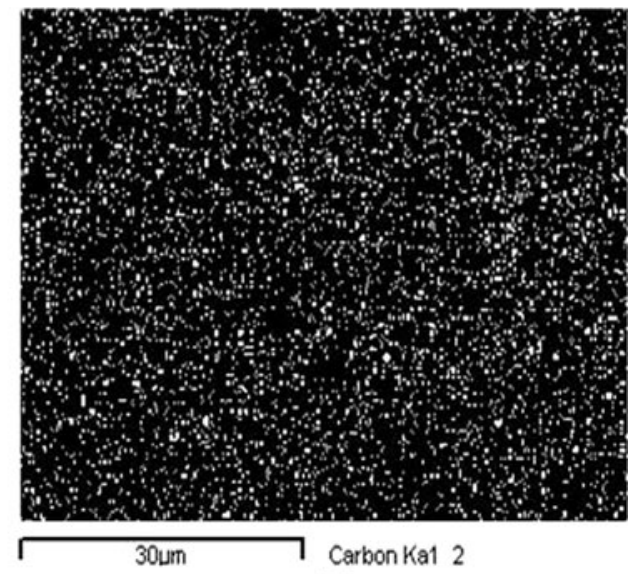

(b) $\mathrm{C}$

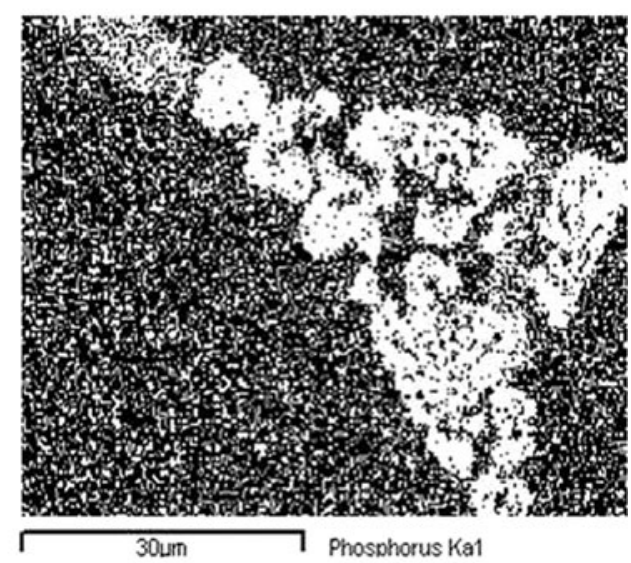

(d) $\mathrm{P}$ 
Fig. 12 EBSD pattern of $\mathrm{Ni}_{3} \mathrm{P}$ within the $38.1 \mu \mathrm{m}$ interlayer after 6-h hold time and $1,150{ }^{\circ} \mathrm{C}$

(a) image and analysis location,

(b) EBSD pattern, (c) indexing

Fig. 13 Identification of $\mathrm{Mo}_{3} \mathrm{P}$ precipitate within the $38.1 \mu \mathrm{m}$ interlayer after 18 -h hold time at $1,065{ }^{\circ} \mathrm{C}$ bonding temperature

(a) image and analysis location, (b) EBSD pattern, (c) indexing
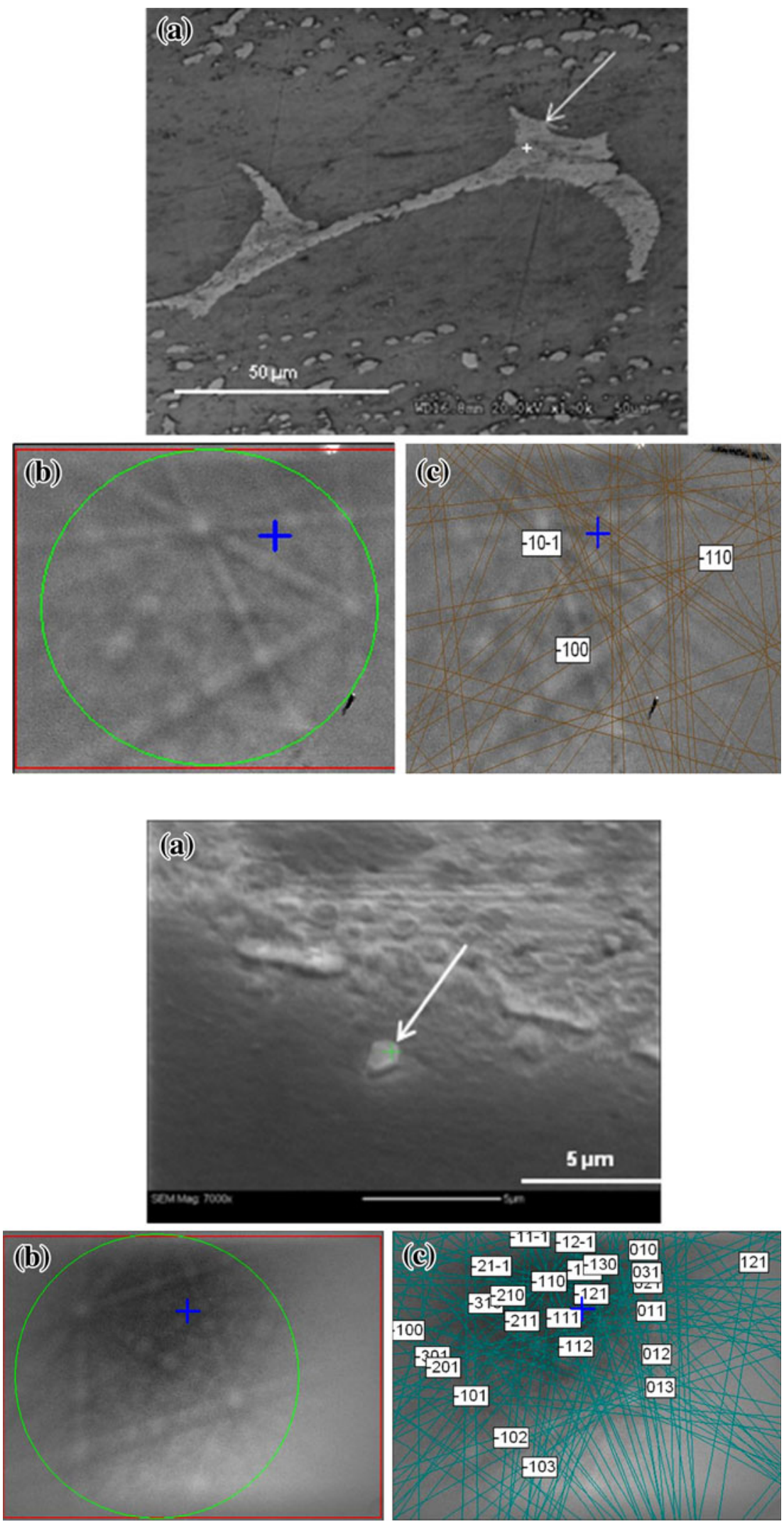

MoNiP at 14-h hold time with bonding temperature (a) image and analysis location, (b) EBSD pattern, (c) indexing
Fig. 14 Phase identification of $25.4 \mu \mathrm{m}$ interlayer at $1,150{ }^{\circ} \mathrm{C}$

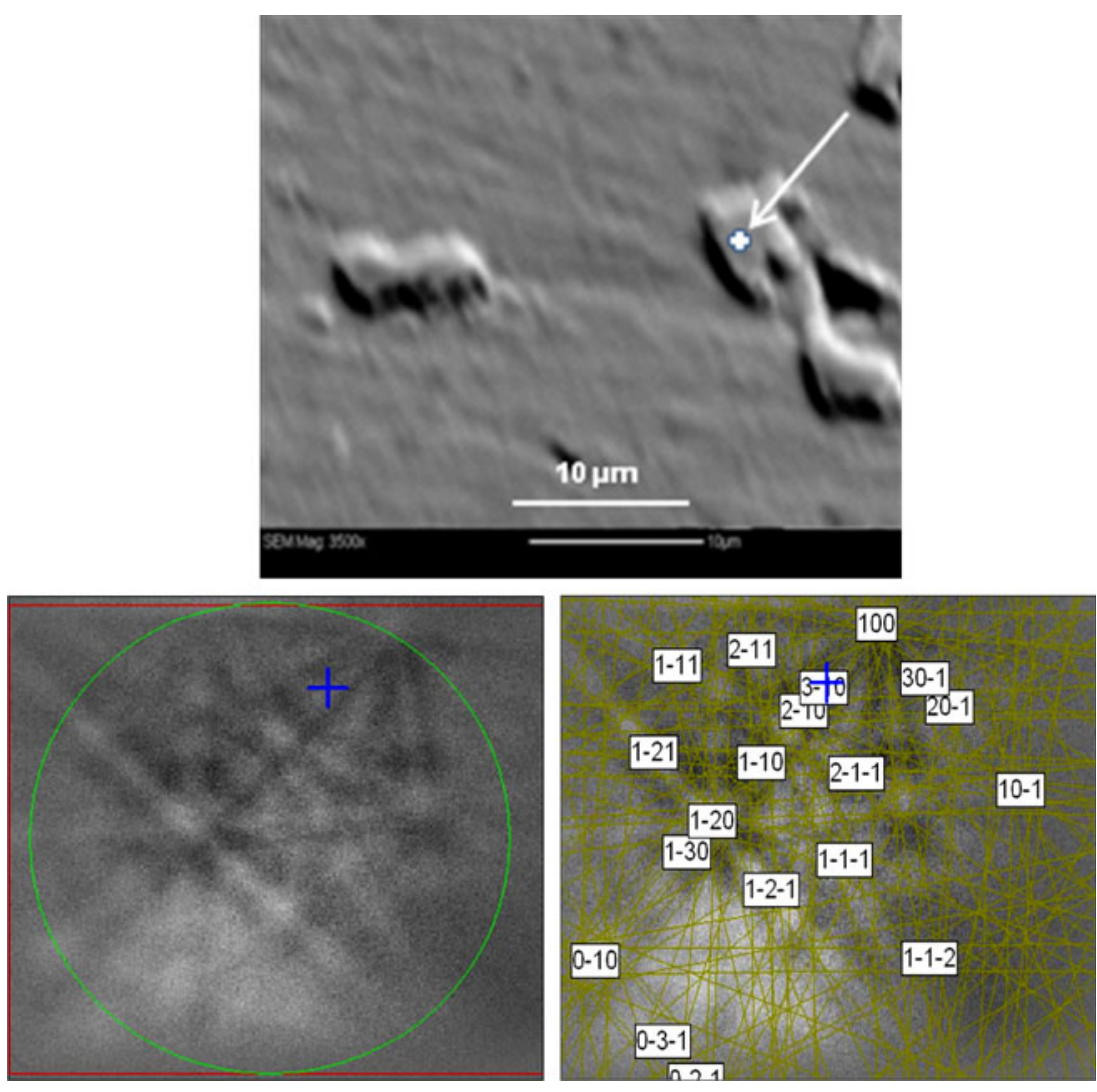

The formation of $\mathrm{Mo}_{3} \mathrm{P}$ and $\mathrm{MoP}$ and the various types of Mo-based compounds can be interpreted partly in terms of the role played by molybdenum during the TLP process. Examination of the Mo-P binary phase diagram, at the concentration level of phosphorous in the interlayer, indicates that $\mathrm{Mo}_{3} \mathrm{P}$ precipitation should occur in the diffusion zone. The presence of MoP precipitates identified in this investigation is not evident from the phase diagram. Additional chemical analysis and phase identifications revealed high concentrations of molybdenum at the grain boundaries. The segregation of Mo to the grain boundaries in $\mathrm{Ni}$ base superalloys has already been reported [25, 31, 32 ] and this investigation confirms its occurrence during the TLP process. Such segregation further enhances the precipitation process at the grain boundaries, which are already favorite locations for heterogeneous nucleation, and is probably responsible for the presence of MoP precipitates observed in the diffusion zone. The thermodynamic phase prediction software (FACT) was also used and predicted the formation of $\mathrm{MoP}$ and $\mathrm{Mo}_{3} \mathrm{P}$ precipitates in the diffusion layer for both thicknesses of the interlayer correlating well with the experimental observations. It is believed that, when shorter hold times are used, the concentration of molybdenum decreases because of reactions with phosphorous and nickel thereby leading to the formation of MoP which ultimately results in the observed lower amounts of molybdenum in the diffusion layer.
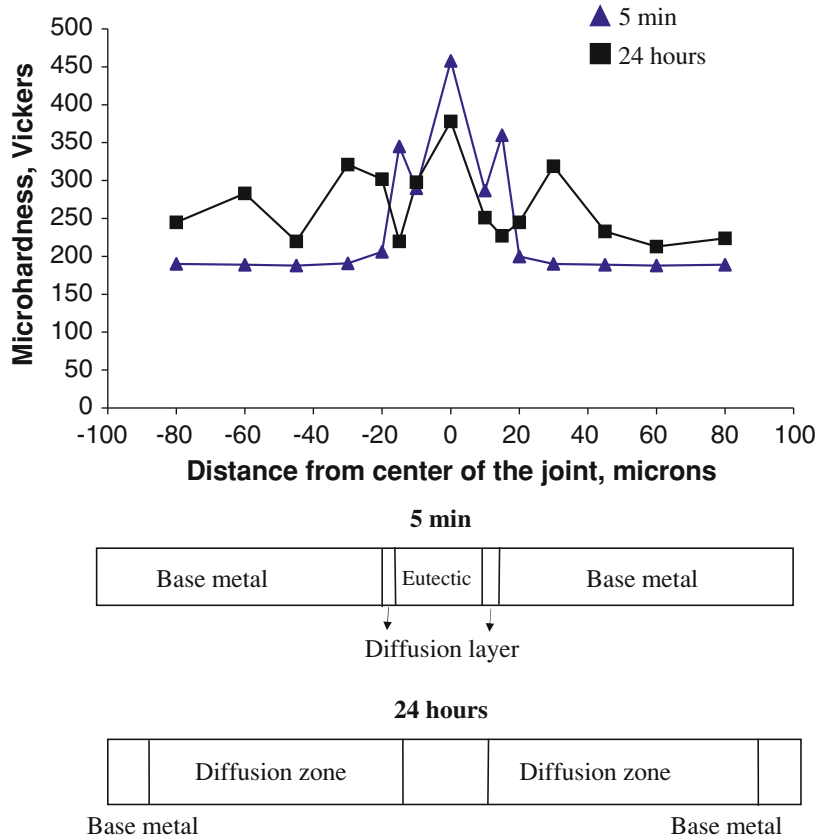

Fig. 15 Microhardness profile of $1,065^{\circ} \mathrm{C}$ at 5-min and 24-h hold time for $25.4 \mu \mathrm{m}$ interlayer

\section{Evolution of the Microhardness During TLP}

Microhardness profiles of TLP joints produced at $1,065{ }^{\circ} \mathrm{C}$, for the thin and the thick interlayer are presented in 
Figs. 15 and 16, respectively. A clear evolution from the center of the joint to the base metal is observed. The hardness level in the sample with 24-h hold time is significantly lower when compared to the sample with 5-min hold time. Figures 17 and 18 illustrate similar data for the higher joining temperature of $1,150{ }^{\circ} \mathrm{C}$. The higher hardness values obtained for the thick interlayer with 24-h hold time are indicative of the presence of the remnants of the non isothermally solidified phase and confirm the findings of the microstructure investigation presented in Figs. 2 and 3.

A comparison between the microhardness measurements in Figs. 15-18 indicates that, for short hold times, the hardness level increased from the base metal into the interlayer. This behavior is probably due to the higher concentration of liquid phase at the center of the interlayer. Interestingly, the microhardness profiles are not significantly affected by the width of the diffusion layer; probably because for short hold times, the size of the diffusion zone is small (Figs. 15, 17). By contrast, significant changes in microhardness levels were observed for the higher bonding temperature. This rapid change in the rate of hardness decrease is associated with faster diffusion rates at higher temperatures. The observed trend was more pronounced for the thin interlayer. Specifically, the hardness for the thin interlayer decreased by $140 \mathrm{HV}$ (from 450 to 310), while it decreased by $120 \mathrm{HV}$ (from 480 to 360) for the thick one. Increasing the hold time results in a significant drop in the hardness level was observed in the specimens joined with the thin interlayer. The drop was more important $(120 \mathrm{Hv}$ instead of $80 \mathrm{HV}$ ) when the higher bonding temperature was used.

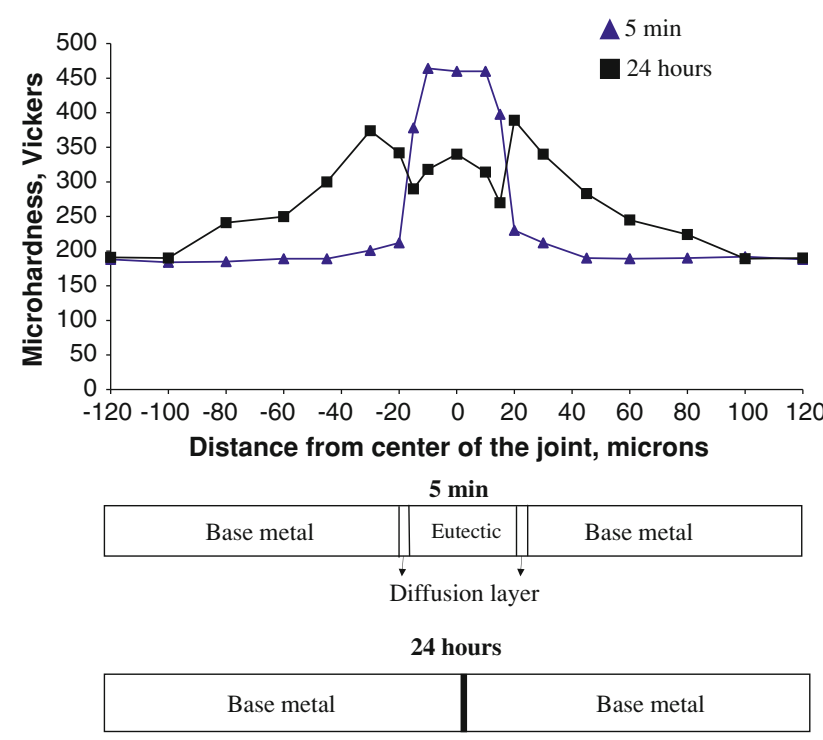

Fig. 16 Microhardness profile of $1,065{ }^{\circ} \mathrm{C}$ at 5-min and 24-h hold time for $38.1 \mu \mathrm{m}$ interlayer
Microhardness results also indicate that the hardness of the thick interlayer continuously increases from the base metal to the interlayer for both bonding temperatures and hold times (Figs. 16, 18). Interestingly, for short hold times, the average value of the hardness in the interlayer was higher ( $461 \mathrm{HV}$ for $1,065^{\circ} \mathrm{C}$ and $470 \mathrm{HV}$ for $1,150^{\circ} \mathrm{C}$ ) than that in the diffusion zone or the base material. Also, the examination of Figs. 15 to 18 reveals a general trend that with increased hold time, the hardness of the interlayer region decreases, while that of the diffusion
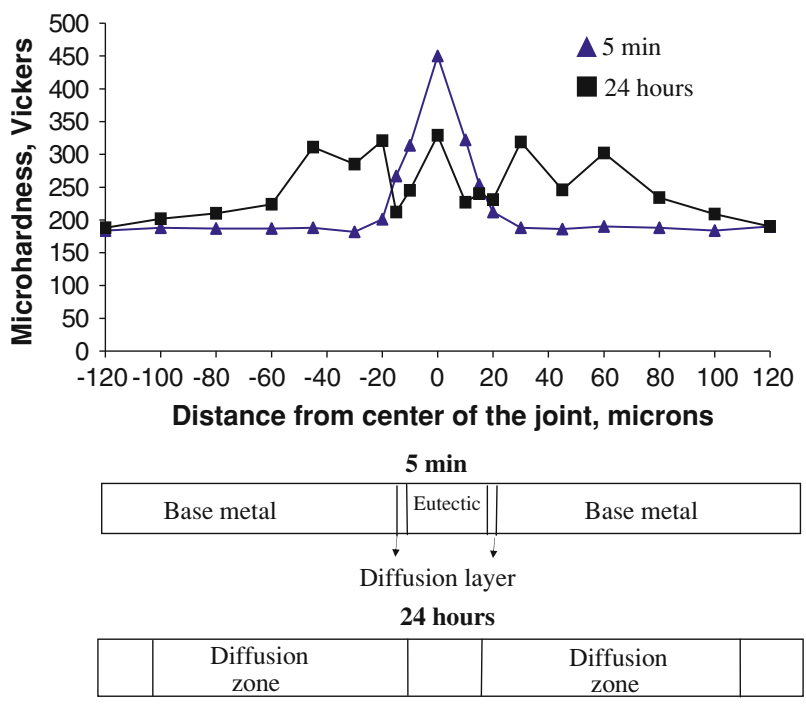

Base metal

Base metal

Fig. 17 Microhardness profile of $1,150{ }^{\circ} \mathrm{C}$ at 5-min and 24-h hold time for $25.4 \mu \mathrm{m}$ interlayer
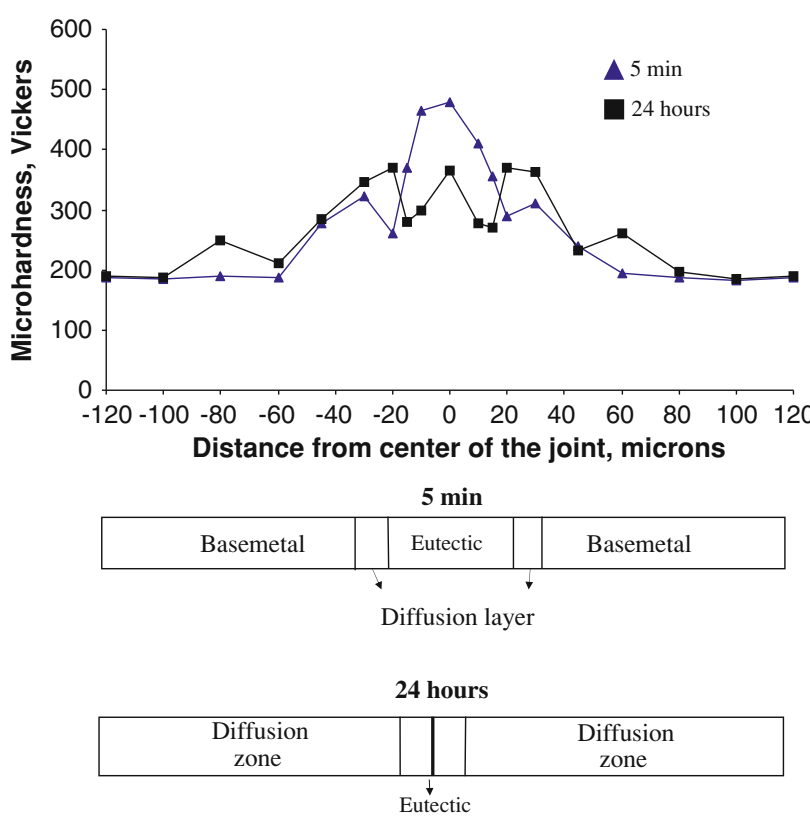

Fig. 18 Microhardness profile of $1,150{ }^{\circ} \mathrm{C}$ at 5-min and 24-h hold time for $38.1 \mu \mathrm{m}$ interlayer 
zones increases. This is clearly indicative of more diffusion of phosphorus away from the interlayer and the formation of precipitates in the diffusion zone with increased hold times. Under these conditions, the most uniform hardness profile was obtained for the samples joined using the thin interlayer TLP bonded at $1,150{ }^{\circ} \mathrm{C}$ for $24 \mathrm{~h}$.

\section{Conclusions}

TLP bonding process of Alloy 617 using Ni-P filler metal was studied. The kinetics of elimination of the non isothermally solidified phase were quantified for two thicknesses of interlayer and the influences of temperature and hold time documented. Isothermal solidification is complete after $18 \mathrm{~h}$ for the $25.4-\mu \mathrm{m}$-thick interlayer at $1,065{ }^{\circ} \mathrm{C}$, while even after $24 \mathrm{~h}$ it is not completed for the $38.1 \mu \mathrm{m}$ interlayer. Precipitates with irregular, and in a few cases with blocky morphologies were observed in the diffusion zone. The precipitates were present at the grain boundaries as well as within the grains. Phase identification results showed that only $\mathrm{Ni}_{3} \mathrm{P}$ was present in the solidified structure of the interlayer. The presence of MoP, MoNiP, $\mathrm{Mo}_{3} \mathrm{P}, \mathrm{Ni}_{3} \mathrm{P}, \mathrm{M}_{23} \mathrm{C}_{6}$, and $\mathrm{TiC}$ precipitates was revealed in the diffusion layer. Phosphides and carbides were observed at the grain boundaries and within the grains. Microhardness analyses indicated that short hold times had the highest impact on hardness variations under all experimental conditions. The most uniform hardness profile was obtained with the $25.4-\mu \mathrm{m}$-thick interlayer at $1,150{ }^{\circ} \mathrm{C}$ and 24-h hold time.

\section{References}

1. P. Ganesan, G.D. Smith, D.H. Yates, Performance of Inconel 617 in actual and simulated gas turbine environments. Mater. Manuf. Process. 10(5), 925-938 (1995)

2. M.K. Ali, M.S.J. Hashmi, B.S. Yilbas, Fatigue properties of the refurbished INCO-617 alloy. J. Mater. Process. Technol. 118, 45-49 (2001)

3. G.L. Erickson, Superalloy developments for aerospace and industrial gas turbines. Advanced materials and coating for combustion turbine, in Proceeding of ASM (Pittsburgh, PA, 1993), pp. 29-41

4. W.L. Mankins, J.C. Hosier, T.H. Bassford, Microstructure and phase stability of Inconel 617. Metall. Trans. B 5B(12), 2579-2590 (1974)

5. T.H. Bassford, T.V. Schill, A review of Inconel alloy 617 and its properties after long-time exposure to intermediate temperatures, in Applications of Materials for Pressure Vessels and Piping, vol. 10, ed. by G.V. Smith (ASME, 1979), pp. 1-12

6. J.C. Hosier, D.J. Tillack, Inconel alloy 617 new high temperature alloy. Metals Eng. Q. 12(3), 51-55 (1972)

7. U. Bruch, D. Schuhmacher, P.J. Ennis, Tensile and impact properties of candidate alloys for high temperature gas cooled reactor applications. Nucl. Technol. 66, 357-362 (1984)
8. "Inconel alloy 617", Product Information, Huntington alloys Inc., Huntington, West Virginia (1979)

9. S. Steuer, S. Piegert, M. Frommherz, R.F. Singer, A. Scholz, Transient liquid phase bonding of pairings of parent superalloy material with different composition and grain structure. Adv. Mater. Res. 278, 454-459 (2011)

10. M.A. Arafin, M. Medraj, D.P. Turner, P. Bocher, Transient liquid phase bonding of nickel superalloys with $\mathrm{BNi}-2$ : modeling and experimental investigations. Mater. Sci. Eng. A 447, 125-133 (2007)

11. W.F. Gale, D.A. Butts, Transient liquid phase bonding. Sci. Technol. Weld. Join. 9(4), 283-300 (2004)

12. M. Pouranvari, A. Ekrami, A.H. Kokabi, Effect of bonding temperature on microstructure development during TLP bonding of a nickel base superalloy. J. Alloys Compd. 469, 270-275 (2009)

13. X. Wu, R.S. Chandel, H. Li, Evaluation of transient liquid phase bonding between nickel base superalloys. J. Mater. Sci. 36, 1539-1546 (2001)

14. W.D. Macdonald, T.W. Eagar, Transient liquid phase bonding processes, in The Metal Science of Joining (The Minerals Metals \& Materials Society, Warrendale, PA, 1992), pp. 93-100

15. A. Ghoneim, O.A. Ojo, Microstructure and mechanical response of transient liquid phase joint in Haynes 282 superalloy. Mater. Charact. 62, 1-7 (2011)

16. A. AlHazaa, T. Khan, I. Haq, Transient liquid phase (TLP) bonding of Al7075 to Ti-6Al-4V alloy. Mater. Charact. 61, 312-317 (2010)

17. H. Kirchhofer, F. Schubert, H. Nickel, Precipitation behavior of $\mathrm{Ni}-\mathrm{Cr}-22 \mathrm{Fe}-18 \mathrm{Mo}$ (Hasrelloy-X) and Ni-Cr-22Co-12Mo (Inconel 617) after isothermal aging. Nucl. Technol. 66, 139-148 (1984)

18. S. Kihara, J.B. Newkirk, A. Ohtomo, Y. Saiga, Morphological changes of carbides during creep and their effects on the creep properties of Inconel 617 at $1000{ }^{\circ} \mathrm{C}$. Metall. Trans. A 11A, 1019-1031 (1980)

19. F. Jalilian, M. Jahazi, R.A.L. Drew, Microstructural evolution during transient liquid phase bonding of Inconel 617 using Ni-SiB filler metal. Mater. Sci. Eng. A 423, 269-281 (2006)

20. K. Saida, Y. Zhou, T.H. North, The influence of base metal grain size on isothermal solidification during TLP brazing of nickel. J. Mater. Sci. 28, 6427-6432 (1993)

21. T. Shinmura, K. Ohsasa, T. Narita, Isothermal solidification behavior during the transient liquid phase bonding process of nickel using binary filler metals. Mater. Trans. 42(2), 292-297 (2001)

22. Y. Nakao, K. Nishimoto, K. Shinozaki, C.Y. Kang, Analysis of isothermal solidification process on transient liquid insert metal diffusion bonding. Q. J. Jpn. Weld. Soc. 7, 213-219 (1989)

23. Y. Zhou, T.H. North, Z. Wang, TLP brazing of nickel numerical modeling and experimental verification, in 3rd International SAMPE Technical Conference (1992), pp. m611-m621

24. W.F. Gale, E.R. Wallach, Microstructural development in transient liquid - phase bonding. Metall. Trans. A 22A(10), 2451-2457 (1991)

25. M.K. Miller, I.M. Anderson, L.M. Pike, D.L. Klarstrom, Microstructural characterization of Haynes $242^{\mathrm{TM}}$ alloy. Mater. Sci. Eng. A A327, 89-93 (2002)

26. Y.Q. Li, J.Y. Liu, Interaction of carbon, boron and sulphur in superalloys. High Temp. Technol. 8(4), 278-282 (1990)

27. X.L. He, M. Djahazi, J.J. Jonas, J. Jackman, The non-equilibrium segregation of boron during the recrystallization of $\mathrm{Nb}$-treated HSLA steels. Acta Metall. Mater. 39(10), 2295-2308 (1991)

28. O.F. Kimball, G.Y. Lai, G.H. Reynolds, Effects of thermal ageing on the microstructure and mechanical properties of a commercial Ni-Cr-Co-Mo alloy (Inconel 617). Metall. Trans. A 7A, 1951-1952 (1976) 
29. T. Takahashi, J. Fujiwara, T. Matsushima, M. Kiyohawa, I. Morimoto, T. Watanabe, Analysis of precipitated phase in heat treated Inconel alloy 617. Trans. ISIJ 18, 221-224 (1978)

30. T.B. Massalski, Binary Alloy Phase Diagrams, vol. 3 (ASM International, Materials Park, OH, 1990)

31. J. Dong, M. Zhang, X. Xie, R.G. Thompson, Interfacial segregation and cosegregation behaviour in a nickel-base alloy 718 . Mater. Sci. Eng. A A328, 8-13 (2002)
32. D. Blavette, P. Duval, L. Letellier, M. Guttmann, Atomic scale APFIM and TEM investigation of grain boundary microchemistry in astroloy nickel base superalloys. Acta Mater. 44(12), 4995-5005 (1996) 